\title{
The Number of Transects Required to Compute a Robust PHABSIM Habitat Index
}

\author{
Thomas R. Payne ${ }^{(1)}$, Steven D. Eggers ${ }^{(1)}$, and \\ Douglas B. Parkinson ${ }^{(2)}$
}

Corresponding author: Thomas R. Payne,trpa@northcoast.com

\begin{abstract}
The value of the number of transects within a segment of an instream flow study that will generate a stable relationship between the PHABSIM habitat index and discharge is examined. Over 600 instream flow studies were reviewed to determine the common practice standard, showing a median number of eight transects per four mile reach. Since the number of study transects varies by length of reach and purpose of study, transects per mile were computed as a more standardized value, with a median result of 2.32 transects per mile for 552 reaches. Studies conducted for water rights claims (255) had a median of 1.30 transects per mile and those conducted for project evaluations (259) had a median of 4.17 transects per mile. Several high transect number data sets were also systematically subsampled to determine how many transects are required to produce a robust habitat index function. This analysis showed that approximately 18-20 transects will in most cases yield a result nearly identical to one obtained using 40-70 transects per segment. When used for time series analysis and comparison of flow alternatives, remaining small differences in the functions would be inconsequential. If used for standard setting purposes, however, the differences could affect flow recommendations and more transects are likely to be necessary.
\end{abstract}

Key words. - Phabsim, IFIM, transect number, habitat modeling, weighted surface area, instream flow

\section{INTRODUCTION}

Standard one-dimensional hydraulic simulation and aquatic habitat modeling using the Physical Habitat Simulation (PHABSIM) system of the Instream Flow Incremental Methodology (IFIM) is based on data acquired along cross-sectional transects.
Transects are typically placed in areas representative of larger stream segments, either by selection of representative reaches or through a process called habitat mapping (Bovee 1997; Bovee et al. 1998). After hydraulic data is collected on the transects, hydraulic models are constructed and calibrated over a range of flows, and results are linked with

(1) Thomas R. Payne \& Associates, P.O. Box 4678, Arcata, CA 95518

(2) Douglas Parkinson \& Associates, P.O. Box 131, Bayside, CA 95524 
aquatic species habitat suitability criteria to produce an index to habitat suitability in relation to flow, commonly called weighted usable area or relative suitability index. This index is then interpreted to evaluate the impact of alternative flow regimes on aquatic resources.

The number of transects believed sufficient to generate the habitat index has never been explicitly identified in the IFIM literature. Numeric guidance is lacking because a "sufficient" number can vary widely due to differences in study objectives, diversity of channel form, changing patterns of hydraulics and aquatic habitat, behavioral use of habitat by target species, limitations in available time or budget, and the history of study team experience. For example, when all other factors are equal, a fairly uniform, channelized stream may be judged well represented by fewer than ten transects, while a highly variable or braided stream may be felt to need a much larger number of transects to account for the higher range of habitat complexity.

The original perception of riverine habitat representation using PHABSIM is described in Instream Flow Information Paper No. 5 (Bovee and Milhous 1978). For any given stream segment, study sites were selected on the basis of their "representation" of the overall segment. Part of the selection process was intended to sample a stream length approximately 10 to 14 times the average channel width. This sample length derived from general alluvial river morphol- ogy precepts on the spacing of successive riffles at about 5 to 7 times the average channel width (Leopold et al. 1964), plus the goal of sampling two complete riffle and pool sequences (presumably for replication).

Within this study site, placement of transects was governed by two principles (Bovee and Milhous 1978); first, to sample discrete types of habitat (i.e. pools, riffles, runs), which covers the purpose for the study, and second, to sample each hydraulic control, which was required by the prevalent hydraulic model. The placement procedure started with mandatory transects at hydraulic controls, followed by transects in remaining major habitat types. If a high level of detail is desired, additional transects can be used to define transitional habitat areas (Bovee and Milhous 1978). Admonitions about the total number of transects are quite specific in all instances where the issue is addressed:

"At this stage the field crew must resist the temptation of proliferating the area with cross sections. As a general rule, never use two cross sections where one would suffice." (Bovee and Milhous 1978)

"The tendency to dot the landscape with headstakes becomes very strong and must be resisted with an iron will. Remember that the greater the detail with which a reach is modeled, the more dissimilar from adjacent reaches it becomes."

(Bovee and Milhous 1978) 
"There is a powerful tendency to collect as much data as possible for any study, expecially if someone else is paying for it."

(Milhous 1990)

The resulting total number of transects placed within a representative study site using the original vision was not provided, but if the logic of placement is followed the typical number would be thirteen. This number is derived by assuming there would be one transect in each of the two replicates of three typical major habitat types of pool, riffle, and run in the contiguous site (6), one transect in each transition between the six types (5), and one transect each at the upper and lower boundaries of the site (2). Illustrations of transect placement in the IFIM literature, which typically show only a single (not replicate) sequence of habitat units, are consistent with this number. When the concept of habitat mapping for transect placement was developed to supplement the representative reach approach (Morhardt et al. 1983), there was no discussion of any change in total transect number. Transects continued to be placed in major habitat units in proportion to abundance in ways consistent with prior practice and under standard study cost constraints.

Exceptions to what was believed to be standard practice for transect number have surfaced recently in Oregon and California and prompted the preparation of this analysis. Instead of $6,10,12$ or 14 transects per river segment, state and federal agencies have been requiring 30,45 , or even more. A new strategy of sampling three each of every habitat type exceeding a minimum abundance (5$10 \%$ by length) has emerged in these States, with three transects in each sampled unit, a procedure which can result in oversampling infrequent types and undersampling abundant types. Justification for this intensity of data collection has been sparse, mostly centered on the opinions of statisticians unfamiliar with PHABSIM, indirect comparisons between one and two-dimensional modeling sampling rates, and an increased sense of pyschological comfort in the quality of the studies. There has been little room for discussion or negotiation, and even direct threats made to deny Section 401 water quality certification if these sampling requirements are not followed.

\section{LITERATURE REVIEW}

There is a relatively high potential for low numbers of transects to generate inaccurate habitat index values on the one hand and high costs associated with what might be later found to be an excess number of transects on the other. Given the importance of balance between accuracy and cost for PHABSIM studies, there are few analyses that have examined the question of minimum suitable transect number. Morhardt (1986) plotted habitat index functions for 9 transects placed in different habitat types and concluded that errors or bias in the 
weight assigned each transect could affect the composite function. An evaluation of the value of transects appears in the PHABSIM User's Guide (Milhous 1990), where habitat index functions for several species were computed from a set of 24 transects and visually compared to functions for a subsample of 4 transects (one per habitat type). With some minor reservations, the Guide concluded that "the shape of the relationships are similar..." and the "number of cross sections can be relatively small..."

Simonson et al. (1994) investigated the optimal number and spacing of transects needed to characterize the mean values of 11 commonly measured stream habitat variables (although not the PHABSIM habitat index). Between 35 and 40 transects were placed at equal intervals one mean stream width (MSW) apart in 86 study sites on 58 Wisconsin streams. The study was designed to cover at least three riffle-pool sequences and include multiple transects within each habitat type. For all streams and habitat variables combined, 20 transects spaced at $2 \mathrm{MSW}$ computed means accurate within $5 \%$ of the true mean $95 \%$ of the time. With 13 transects, $85 \%$ of the means were within $5 \%$ of the true means. In general, larger streams required more transects than smaller streams. Of the variables commonly used in PHABSIM, the mean of 5 velocity measurements per transect was $5 \%$ outside the true mean in 18 of 84 sites based on 20 transects. Mean depth (4 samples per transect) for 20 transects was not within $5 \%$ of the true mean for only 5 of 86 sites. Visual estimates of cover and substrate within one-half MSW of each transect required very few (10 or less) transects to accurately describe the true mean.

Williams (1996) attempted to produce confidence intervals around a composite habitat index function through bootstrap-sampling individual index functions from 15 transects within three habitat type strata. Bootstrap sampling with replacement from such a small sample size is a poor method for this type of analysis because it assumes that transects within strata are replicates. In reality, transects within strata may generate similar indices but often have an individual character derived from internal habitat diversity. The challenge in developing a river model is to include sufficient diversity without oversampling; bootstrap sampling magnifies rather than absorbs the extent of internal transect diversity. A similar method with the same number of transects and strata was used by Bourgeois et al. (1996). Instead of being useful, both studies essentially confirmed the conclusion reached by Morhardt (1986); that different transect weights will give different composite index functions, most significantly in small sample sizes.

A study by Bovee (1997) on transect number minimized the problematic effect of resampling the same transects by either randomly or systematically sampling the habitat index 
functions of 3 or 5 transects in a population of 20 placed in a single $61 \mathrm{~m}$ $(200 \mathrm{ft})$ habitat unit. The results showed strong similarities between habitat functions of the subsamples and the total population, with little difference between the two sample sizes or the sampling strategy. Bovee concluded that pocket water, a complex habitat type containing a wide variety of depths and velocities, can be accurately described with 3 to 5 transects. A composite habitat index function from multiple habitat strata should also reduce the influence of variability found within any given strata.

\section{METHODS}

\section{Standard Practice for Transect Number}

For the past two decades, Thomas R. Payne \& Associates has been building an archive library of instream flow studies from various sources, including contracted work, interlibrary loan, internet searches, and personal contacts. The library now numbers over 600 references, and is roughly estimated to contain between onefifth and one-fourth of all PHABSIM studies. This meta-data set of studies was examined to determine what number of transects has been typical in the application of the IFIM and PHABSIM since the methods were developed. Report sections on study design, segment definition, reach stratification, study site selection, and transect placement were reviewed to extract data on the number of transects per study site, reach, and segment, and to compute the number of transects per unit of represented stream length. Also noted was the reporting entity and study purpose, year of study, and geographic region, to possibly identify trends in transect number over time, space, or political boundaries.

\section{Transect Number Sensitivity Testing}

Lack of resistance to the tendency for transects to proliferate has resulted in a number of instream flow studies containing high sample sizes within several habitat-type strata. Table 1 shows eight rivers with large numbers of transects that were subsampled within strata to test the effect of transect sample size on composite habitat index functions. Rivers are identified only by stream type and characteristics to minimize regulatory conflicts.

Habitat index functions were created from these hydraulic files using a range of habitat suitability criteria. Four sets of generic criteria for depth and velocity were created (deep/ slow, deep/fast, shallow/slow, shallow/fast) to include a wide range of potential results (Table 2). The channel index variable for substrate and/or cover suitability was set to 1.0 , since (with some exceptions) it typically only affects the amplitude of the habitat index. Use of actual criteria for real aquatic species was avoided, since 
Table 1. - Study Rivers by Stream Type (Large Low (LL) Gradient, Large High (LH) Gradient, Small High (SH) Gradient), Mean Annual Flow in $\mathrm{m}^{3} / \mathrm{s}(\mathrm{Q})$, Percent Slope (S), Habitat Strata, Number of Transects in Each Habitat Strata, and Percent of Total Segment Length in Each Habitat Strata for Transect Weighting.

\begin{tabular}{|c|c|c|c|c|c|c|c|c|c|c|c|}
\hline \multirow{2}{*}{$\begin{array}{c}\text { ID } \\
\text { LL1 }\end{array}$} & \multirow{2}{*}{$\begin{array}{c}\text { Q/S } \\
33.2\end{array}$} & \multicolumn{10}{|c|}{ Habitat Strata/Transects by Strata - Percent Habitat by Strata } \\
\hline & & \multicolumn{2}{|c|}{ Pool } & \multicolumn{2}{|c|}{ Run/Glide } & \multicolumn{2}{|c|}{ Riffle } & & & & \\
\hline & 0.12 & 12 & 74.4 & 9 & 19.4 & 6 & 6.2 & & & & \\
\hline \multirow[t]{2}{*}{ LL2 } & 165 & \multicolumn{2}{|c|}{ Pool } & \multicolumn{2}{|c|}{ Run/Glide } & \multicolumn{2}{|c|}{ Riffle } & & & & \\
\hline & 0.06 & 12 & 77.4 & 9 & 11.7 & 8 & 10.9 & & & & \\
\hline \multirow[t]{2}{*}{ LH1 } & 51.3 & \multicolumn{2}{|c|}{ Pool } & \multicolumn{2}{|c|}{ Run/Glide } & \multicolumn{2}{|c|}{ Riffle } & & & & \\
\hline & 1.04 & 27 & 44.4 & 24 & 39.2 & 20 & 16.4 & & & & \\
\hline \multirow[t]{2}{*}{ LH2 } & 41.8 & \multicolumn{2}{|c|}{ Pool } & \multicolumn{2}{|c|}{ Rapid } & \multicolumn{2}{|c|}{ Run } & \multicolumn{2}{|c|}{ Riffle } & & \\
\hline & 0.79 & 10 & 24.6 & 6 & 11.0 & 15 & 39.0 & 11 & 25.4 & & \\
\hline \multirow[t]{2}{*}{$\mathrm{SH} 1$} & 1.0 & \multicolumn{2}{|c|}{ Pool } & \multicolumn{2}{|c|}{ Glide } & \multicolumn{2}{|c|}{ Run } & \multicolumn{2}{|c|}{ Pocket Water $\left(^{*}\right)$} & \multicolumn{2}{|c|}{ Riffle } \\
\hline & 4.13 & 13 & 16.2 & 8 & 7.0 & 5 & 4.0 & 12 & 43.0 & 9 & 29.8 \\
\hline SH2 & 0.5 & \multicolumn{2}{|c|}{ Pool } & \multicolumn{2}{|c|}{ Rock Garden $\left({ }^{* *}\right)$} & \multicolumn{2}{|c|}{ Run } & \multicolumn{2}{|c|}{ Pocket Water } & \multicolumn{2}{|c|}{ Riffle } \\
\hline & 5.13 & 12 & 22.3 & 5 & 8.1 & 2 & 1.0 & 18 & 56.1 & 6 & 12.5 \\
\hline $\mathrm{SH} 3$ & 2.4 & \multicolumn{2}{|c|}{ Pool } & \multicolumn{2}{|c|}{ Rock Garden } & \multicolumn{2}{|c|}{ Run } & \multicolumn{2}{|c|}{ Riffle } & & \\
\hline & 1.40 & 28 & 18.5 & 5 & 18.5 & 9 & 28.6 & 11 & 34.4 & & \\
\hline SH4 & 1.1 & \multicolumn{2}{|c|}{ Pool } & Poc & Vater & & & & & & \\
\hline & 1.53 & 15 & 48.0 & 5 & 27.5 & 11 & 13.4 & 4 & 11.1 & & \\
\hline
\end{tabular}

Table 2. - Generic Habitat Suitability Criteria for Combinations of Depth and Velocity in Deep/Slow, Deep/Fast, Shallow/Slow, and Shallow/Fast.

\begin{tabular}{ccccc}
\hline & Slow & \multicolumn{3}{c}{ Fast } \\
\hline Velocity $\mathrm{m} / \mathrm{s}$ & Suitability & Velocity $\mathrm{m} / \mathrm{s}$ & Suitability \\
0.0 & 1.0 & 0.0 & 0.0 \\
0.1 & 1.0 & 0.25 & 1.0 \\
0.5 & 0.0 & 0.50 & 1.0 \\
& & 1.0 & 0.0 \\
\hline \multicolumn{2}{c}{ Shallow } & & \multicolumn{2}{c}{ Deep } \\
\hline 0.0 & Suitability & Depth $\mathrm{m}$ & Suitability \\
0.25 & 0.0 & 0.0 & 0.0 \\
0.5 & 1.0 & 0.25 & 0.0 \\
1.0 & 1.0 & 0.50 & 1.0 \\
& 0.0 & 1 & 1.0 \\
\hline
\end{tabular}


several of the test rivers remain subject to active proceedings.

Computed habitat indices for individual transects using each of the four generic criteria in each stream were subsampled by 1) plotting all transect habitat index functions by habitat type strata to review similarity and identify outliers (Figures 3 and 6 ), 2) selecting the index function for a single transect from each strata, 3) weighting each index function according to the percent of stream length represented by the strata, 4) summing the weighted index functions to create a sub-set composite, and 5) graphing and visually comparing the result against the composite function of all available transects. For example, in Figure 4 (upper left), the first iteration gave one composite function from four transects, compared to the composite for all 42 transects. The second subsample (upper center) consisted of eight transects, the third 12 , and so on, with each transect weighted by the strata percent divided by the number of transects per strata. This process was completed once using the sequence of odd-numbered transects (Subset $A$ ), and again using even-numbered transects (Subset B), for up to 5 transects (20 total) from each strata. In some cases where fewer than 10 transects (5 odd and 5 even) were available within a strata, the larger sample sizes were completed using transects of the opposing sequence. For rivers where there were only three habitat type strata, sampling was repeated to include 6 transects of each strata per subset (18 total).

Several mathematical or statistical approaches to test differences in the composite indices were examined and discarded as unsatisfactory or unworkable. The absolute (or percentage) difference between the results for any given flow would not indicate if the indices had similar peaks and trends. Tests of sampling differences about a mean (per Simonson et al. 1994) would not apply since habitat indices are not samples of a population, being first derived from a composite of many data points, then adjusted for suitability and weighted by representation, and finally summed. The bootstrap technique with replacement used by Williams (1996) derives broad boundaries for many samplings, some of which contain many duplicate transects, and gives no indication of results from large sample sizes. Divergence testing of indices at specific flows, as done by Bourgeois et al. (1996), does not test single sample results or show whether indices are functionally identical, as they may have the same peak and trend and differ only in amplitude, or diverge only at the outer bounds of extrapolation. This analysis therefore relies on visual comparison of repeat sampling by sample size to derive broad conclusions or recommendations, per Milhous (1990) and Bovee (1997). 


\section{RESULTS}

\section{Standard Practice for Transect Number}

Standard terms for defining instream flow study areas and guiding placement of transects include segment, reach, and study site (Bovee et al. 1998, Stalnaker et al. 1995). A segment is a longer (e.g. hundreds of channel widths) section of stream that is relatively homogeneous in terms of hydrology, geomorphology, and pattern. Segments are the fundamental accounting units for assessing impacts of flow alteration on total habitat and can be characterized by a single habitat index versus flow relationship. A reach is a comparatively short section of stream, one or more of which can be combined to make up a segment. The actual length of a reach is defined by the purpose of the study; in some cases a reach is the site of data collection for a "representative" reach, usually no greater than 5-7 times the channel width in length, and in others reaches are portions of a segment that are more homogeneous in gradient, hydrology, braiding, or other characteristic. A study site is the physical location where transects are placed, whether they are clustered or broadly distributed.

The research of available instream flow studies identified 572 studies which listed reach or segment length, 616 which listed transect number, and 552 which listed both (Table 3). The mean and standard deviation of these study parameters are computed but are of minimal value since widely varying study purposes, reach definitions, and study scope control reach length and transect number. More useful are the median values, which could be considered "typical": 6.44 kilometers for reach length, 8.00 for transect number, 0.69 kilometers per transect, and 1.44 transects per kilometer. The data base, although quite large, was inadequate to derive broader trends in transect number over time, or in transect number differences within specific geographic regions.

Table 3. - Sample Size, Mean, Standard Deviation, and Median for Reach Length, Transect Number, Kilometers per Transect, and Transects per Kilometer.

\begin{tabular}{|l|c|c|c|c|}
\hline & $\begin{array}{c}\text { Studies With } \\
\text { Reach Length }\end{array}$ & $\begin{array}{c}\text { Studies With } \\
\text { Transect Number }\end{array}$ & $\begin{array}{c}\text { Kilometers } \\
\text { Per Transect }\end{array}$ & $\begin{array}{c}\text { Transects } \\
\text { Per Kilometer }\end{array}$ \\
\hline Sample Size & 572 & 616 & 552 & 552 \\
Mean $^{(3)}$ & $12.60 \mathrm{~km}$ & 10.66 & 1.65 & 2.88 \\
Std. Deviation & 25.10 & 9.71 & 3.56 & 5.23 \\
\hline Median & $6.44 \mathrm{~km}$ & 8.00 & 0.69 & 1.44 \\
\hline
\end{tabular}

(3) Mean statistics on kilometers per transect and transects per kilometer are not mathematical inverses because they are derived from individual study data, not the sums of all data. 


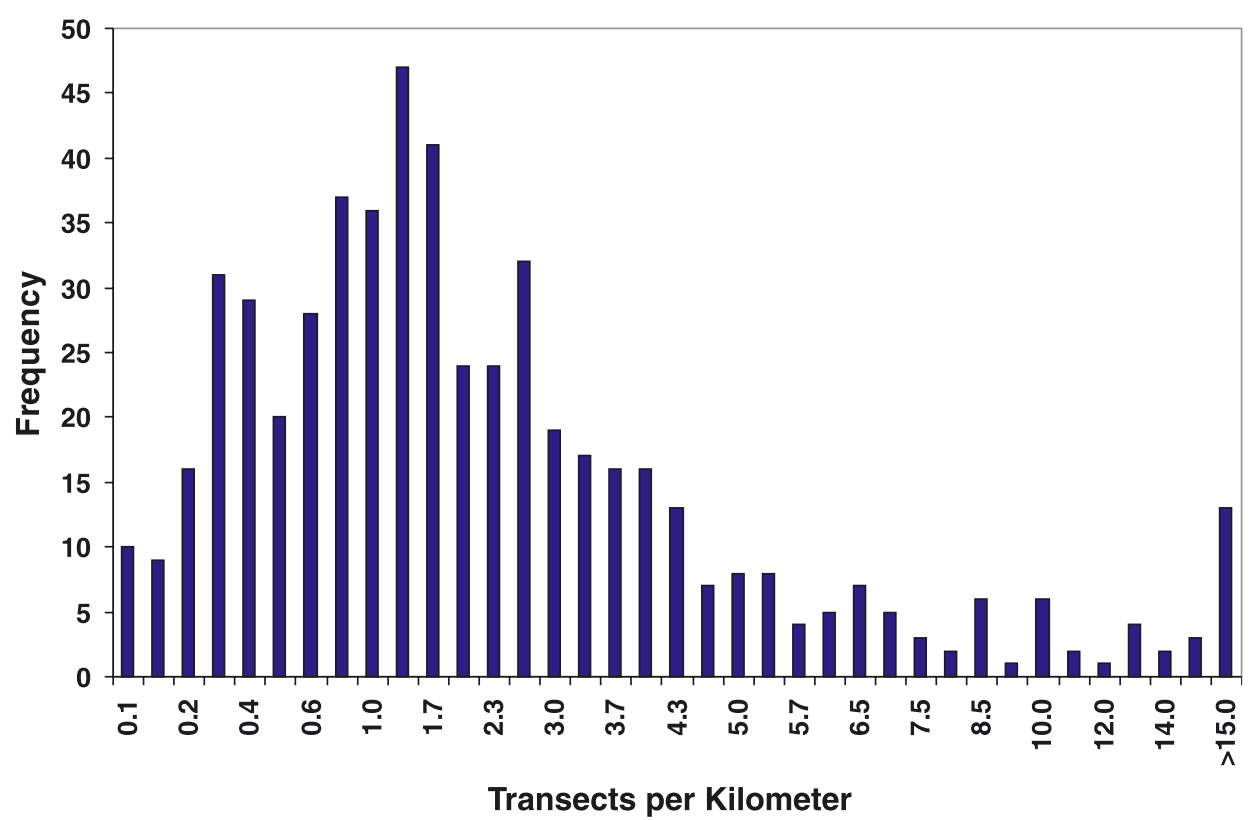

Fig. 1. - Frequency histogram of number of transects per kilometer from 552 PHABSIM studies.

Frequency analysis of the 552 studies for which transects per kilometer could be computed is presented in Figure 1. The values for most studies fell within a range of 0.2 and 4.5 transects per kilometer, with some having as few as one transect every 15 kilometers or more and some with a dozen or more transects over very short distances. When the studies are stratified by identified study purpose, the results are: water rights claims $(46 \%)$, specific project evaluations $(47 \%)$, basin planning $(2 \%)$, and research $(5 \%)$. Sample size, mean, standard deviation, and median for reach length, transect number, transects per transect, and transects per kilometer of water rights claims and project evaluations are pre- sented in Table 4. Reach lengths are longer, number of transects fewer, kilometers per transect greater, and transects per kilometer lower for water rights claim studies than for project evaluation studies. A frequency histogram of transects per kilometer for all studies of these two types is presented in Figure 2.

\section{Transect Number Sensitivity Testing}

As an example of the results obtained from the sensitivity testing, Figure 3 shows the pool, rapid, run, and riffle habitat index functions by transect for one of the larger, higher gradient sample streams (LH2) using the generic deep/fast HSC. Stream LH2 was habitat typed to contain pool 
Table 4. - Sample Size, Mean, Standard Deviation, and Median for Reach Length, Transect Number, Kilometers per Transect, and Transects per Kilometer for all Water Rights (WR) and Project Evaluation (PE) Studies.

\begin{tabular}{|l|c|c|c|c|}
\hline & $\begin{array}{c}\text { Studies With } \\
\text { Reach Length }\end{array}$ & $\begin{array}{c}\text { Studies With } \\
\text { Transect Number }\end{array}$ & $\begin{array}{c}\text { Kilometers } \\
\text { Per Transect }\end{array}$ & $\begin{array}{c}\text { Transects } \\
\text { Per Kilometer }\end{array}$ \\
\hline WR Sample Size & 272 & 280 & 255 & 255 \\
PE Sample Size & 262 & 293 & 259 & 259 \\
\hline WR Mean & $12.53 \mathrm{~km}$ & 7.69 & 2.03 & 1.75 \\
PE Mean & $9.29 \mathrm{~km}$ & 13.88 & 0.70 & 4.10 \\
\hline WR Std. Dev. & 14.69 & 6.85 & 2.19 & 3.81 \\
PE Std. Dev. & 13.04 & 11.31 & 1.13 & 6.14 \\
\hline WR Median & $8.05 \mathrm{~km}$ & 6.00 & 1.23 & 0.81 \\
PE Median & $4.75 \mathrm{~km}$ & 10.00 & 0.39 & 2.59 \\
\hline
\end{tabular}

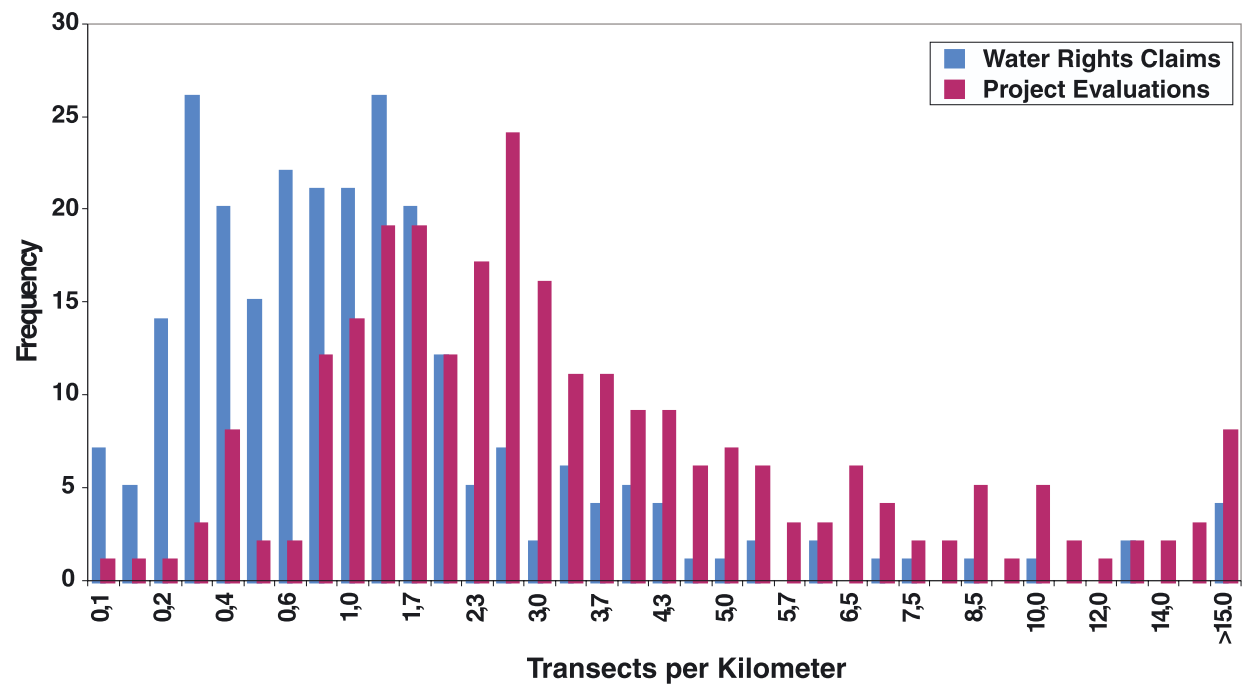

Fig. 2. - Frequency histogram of number of transects per kilometer for 255 studies conducted for water rights claims and 259 conducted for project evaluations.

$(24.6 \%)$, rapid $(11.0 \%)$, run $(39.0 \%)$, and riffle $(25.4 \%)$. Within each of these habitat type strata, most of the functions show similar patterns of re- sponse to changing flow, some diverge from the strata pattern, and some could fit just about as well within the patterns of other strata. 
These results are typical of individual transect index responses, and are caused by hydraulic similarity within strata, lack of habitat type uniformity within individual transects (e.g. part pool, part run), and transects showing either unique attributes (e.g. shallow benches) or transitional characteristics (e.g. riffles turning to runs with increasing discharge).

The successsive addition of transects (weighted by strata) to a composite index function showed progressive convergence towards the full transect index function in both Subset A (e.g. Figure 4) and Subset B (e.g. Figure 5). Eventual convergence should be expected, since the sequence of subsamples would increasingly become a greater proportion of the complete function; both subsets $A$ and $B$ showed this pattern. However, the two subsets also showed convergence towards each other, even though they were (for the most part) composed of indices from different transects. Stability in the habitat index appeared to be reached with approximately 18 to 20 transects, depending on the number of habitat type strata ( 3 , 4 , or 5), variation in HSC (Figure 6) and the inclusion or exclusion of particular outliers (Figures 4, 5, 7, and 8). Dividing the transect indices into an upper set and a lower set and making a similar comparison (results not shown) did not change this conclusion.

This pattern of stability was evident in all sampled streams, whether large or small, low or high gradient, for all four generic HSC (Figures 9-16), with only a few exceptions. The two subset 18-transect samples using shallow/fast HSC in River LL1 (Figure 11, lower left), for example, showed similar trend and magnitude but did not peak at the same flow. The difference is enough to affect standard setting decisions made for flow recommendations but is unlikely to have much influence on recommendations derived from a time series analysis incorporating hydrology.

\section{DISCUSSION}

Several useful trends in the process of stable habitat index creation were revealed through the subsampling of larger data sets. First, in less complex streams with low number of habitat type strata, fewer transects seem to be needed to generate a robust index, provided there are no extreme outliers in the population. The brook studied by Bourgeois et al. (1996) had remarkably similar indices for flats, runs, and riffles and could yield stability with only two or three transects from each strata. Second, highly complex streams with more habitat type strata and very difficult hydraulics still generated a robust index within 20 transects. Those indexes still changing as the sample size approached 20 were streams with a high percent by length (50$70 \%$ ) of a single habitat type, so each successive transect of that type contributed significant weight to the composite index. As individual transect percent contribution by weight fell be- 

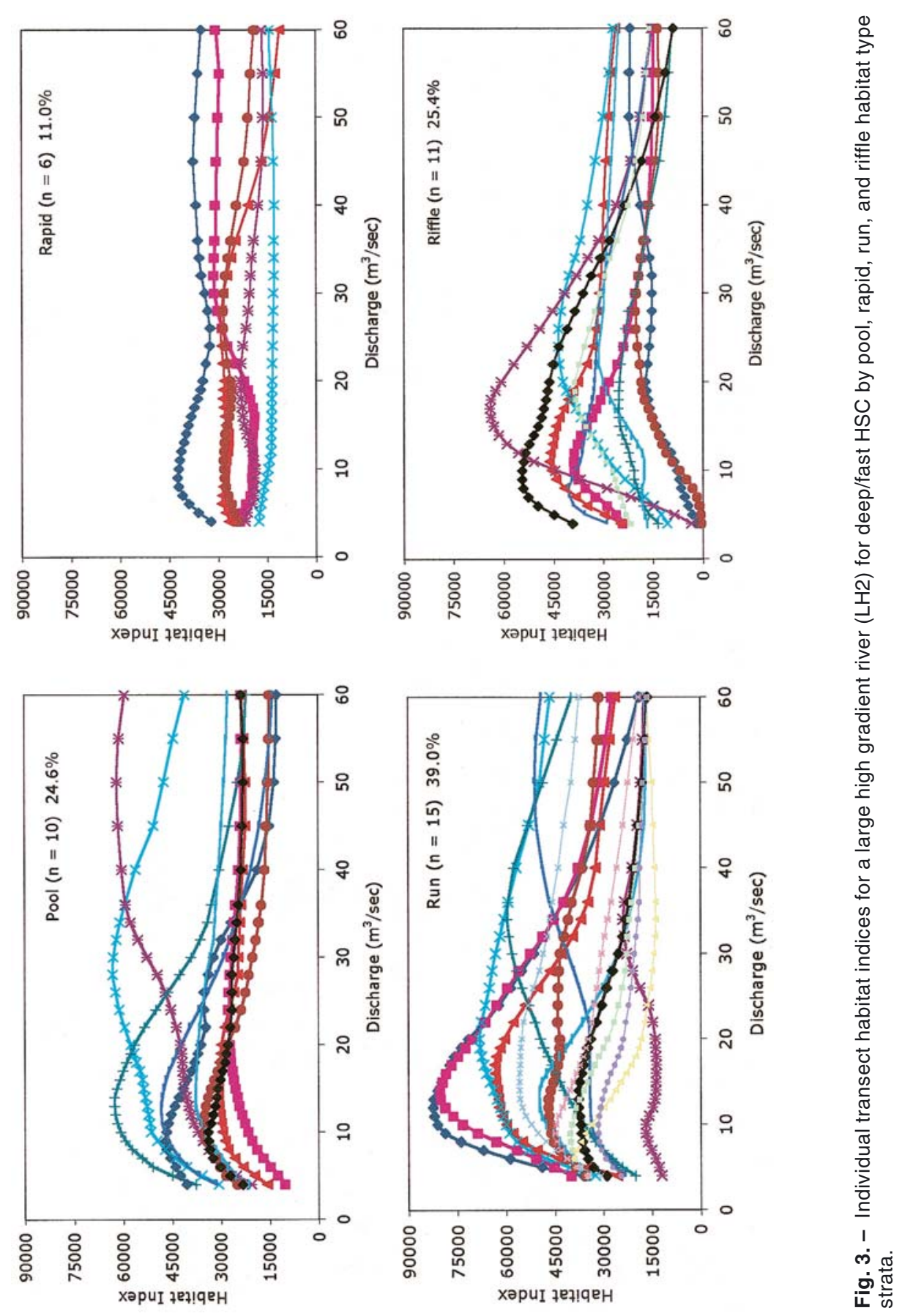


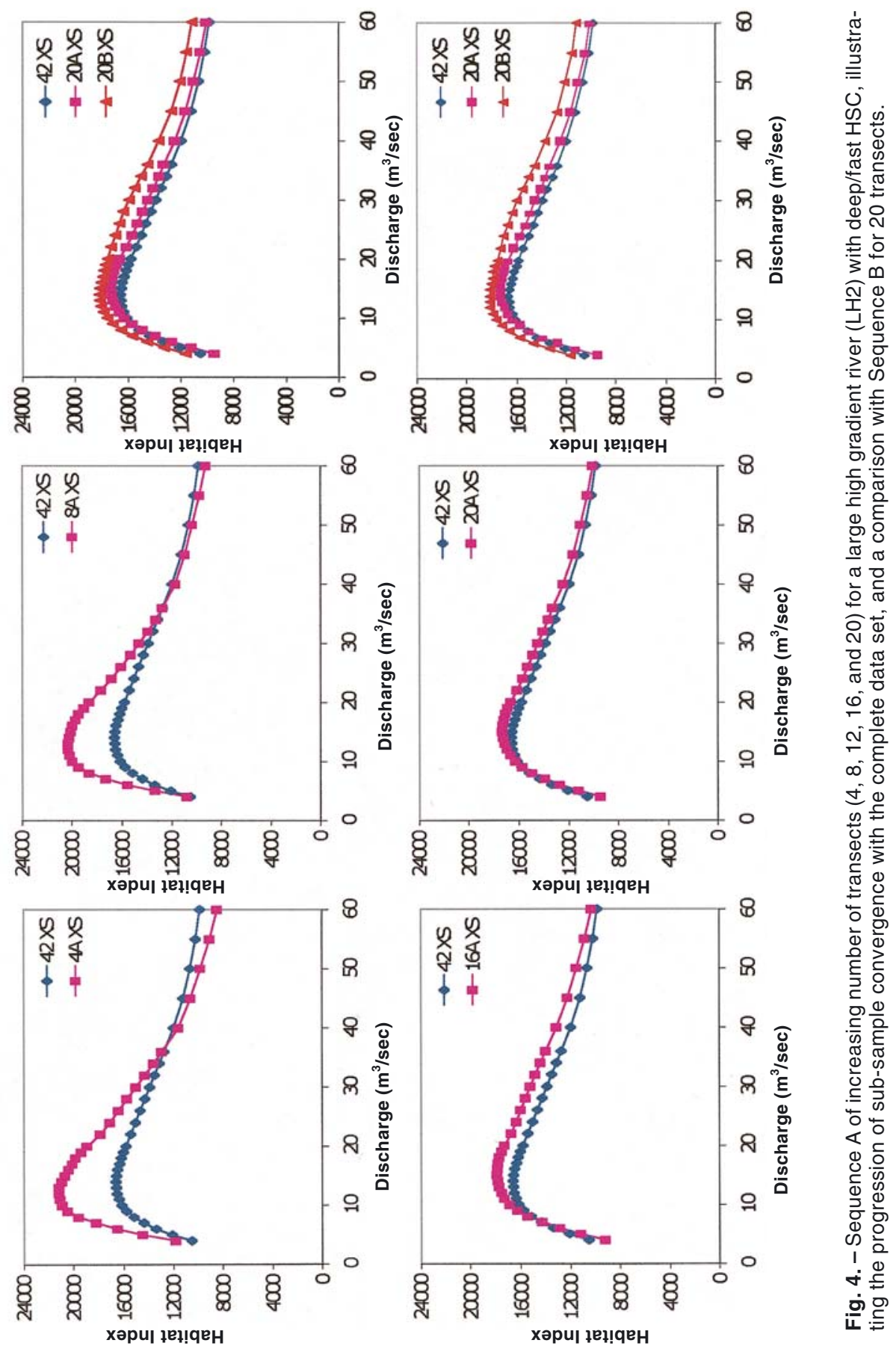




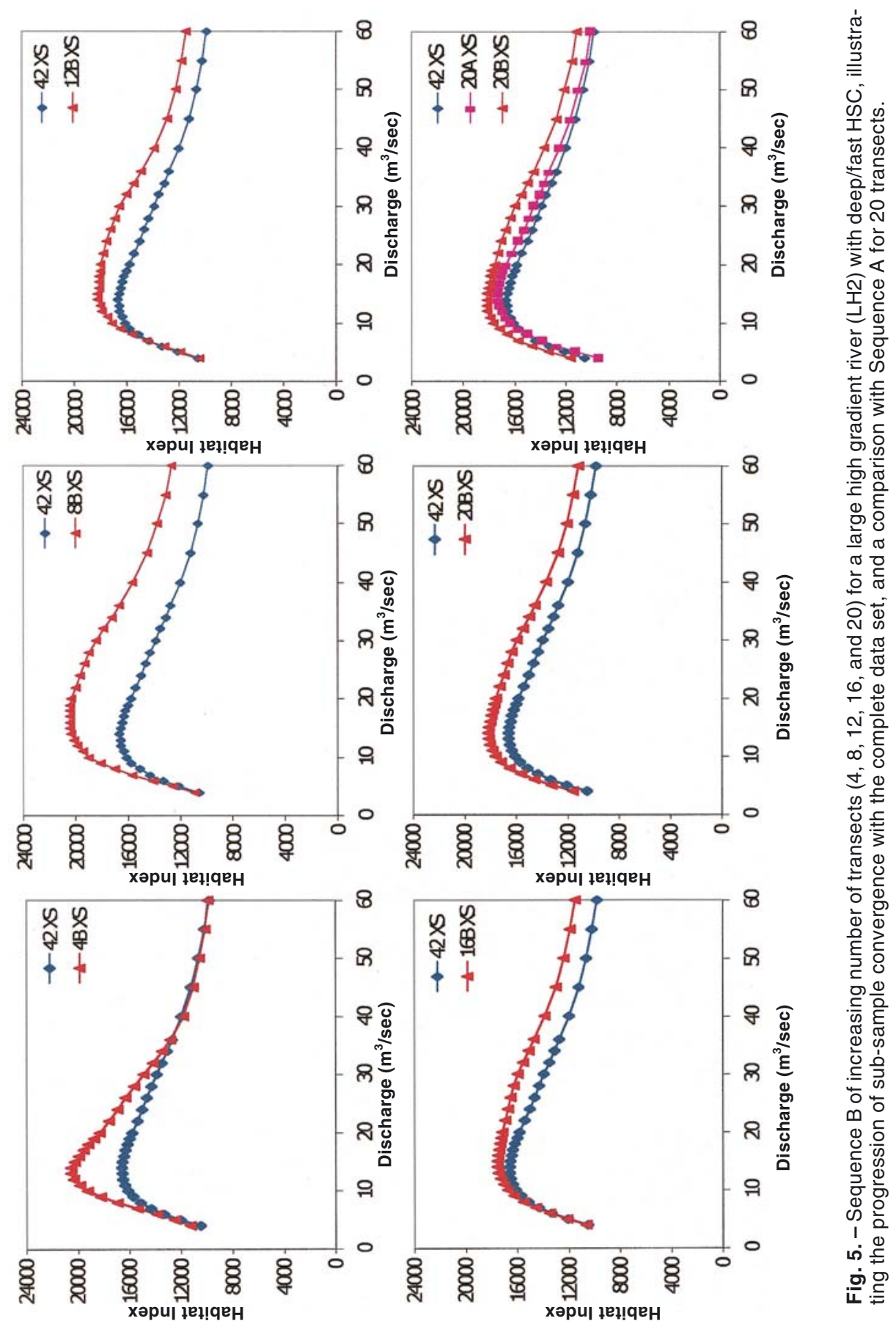



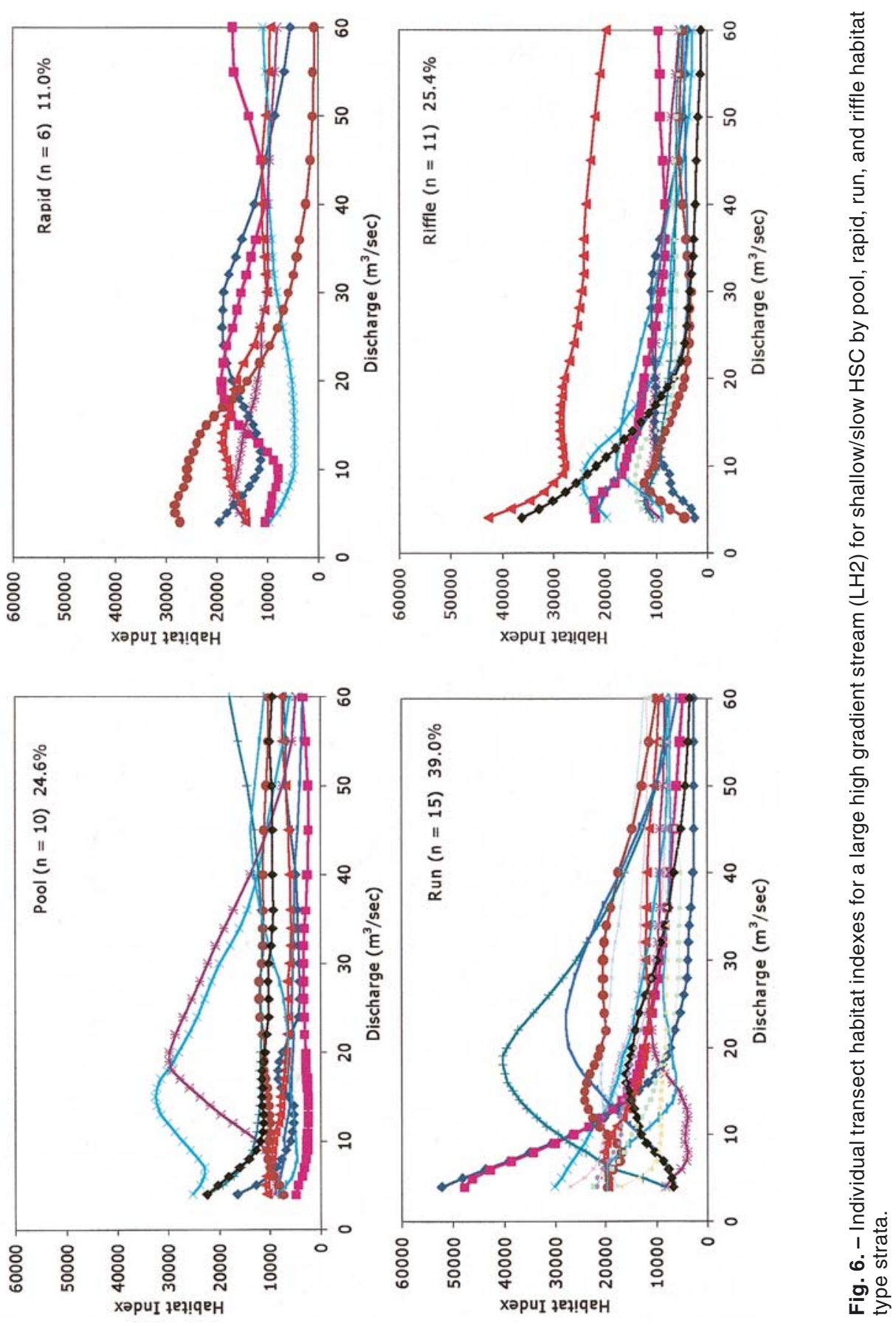


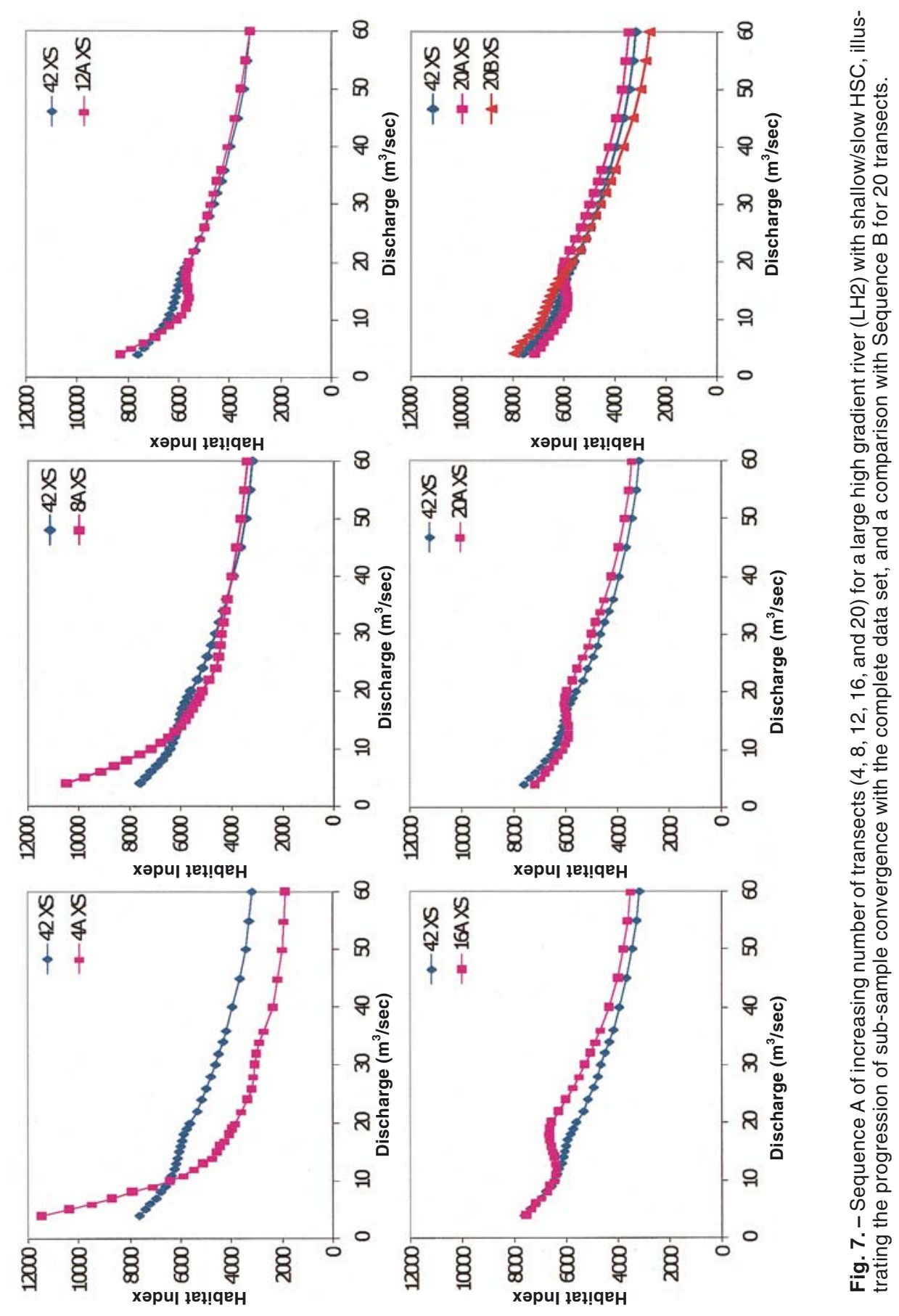




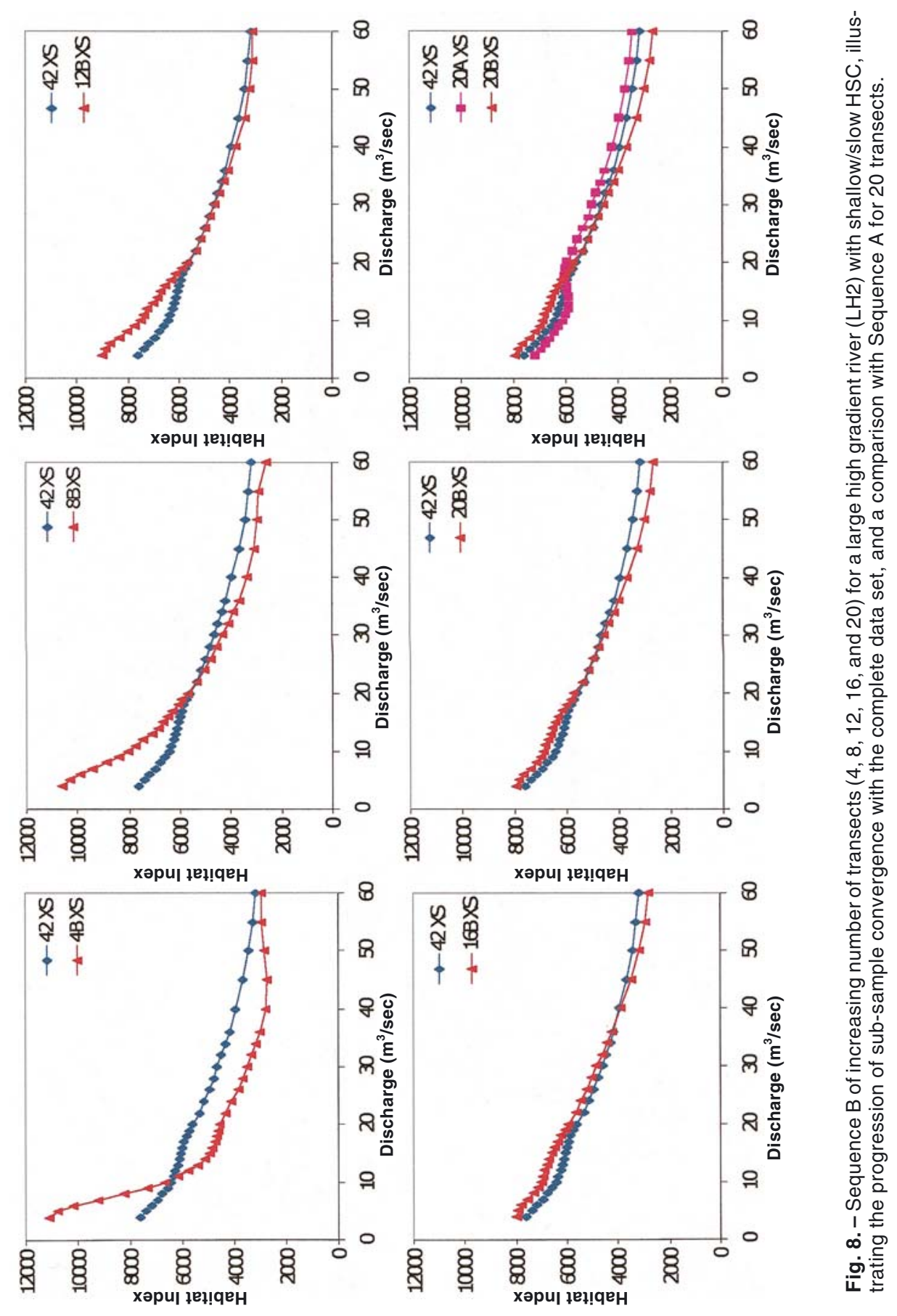



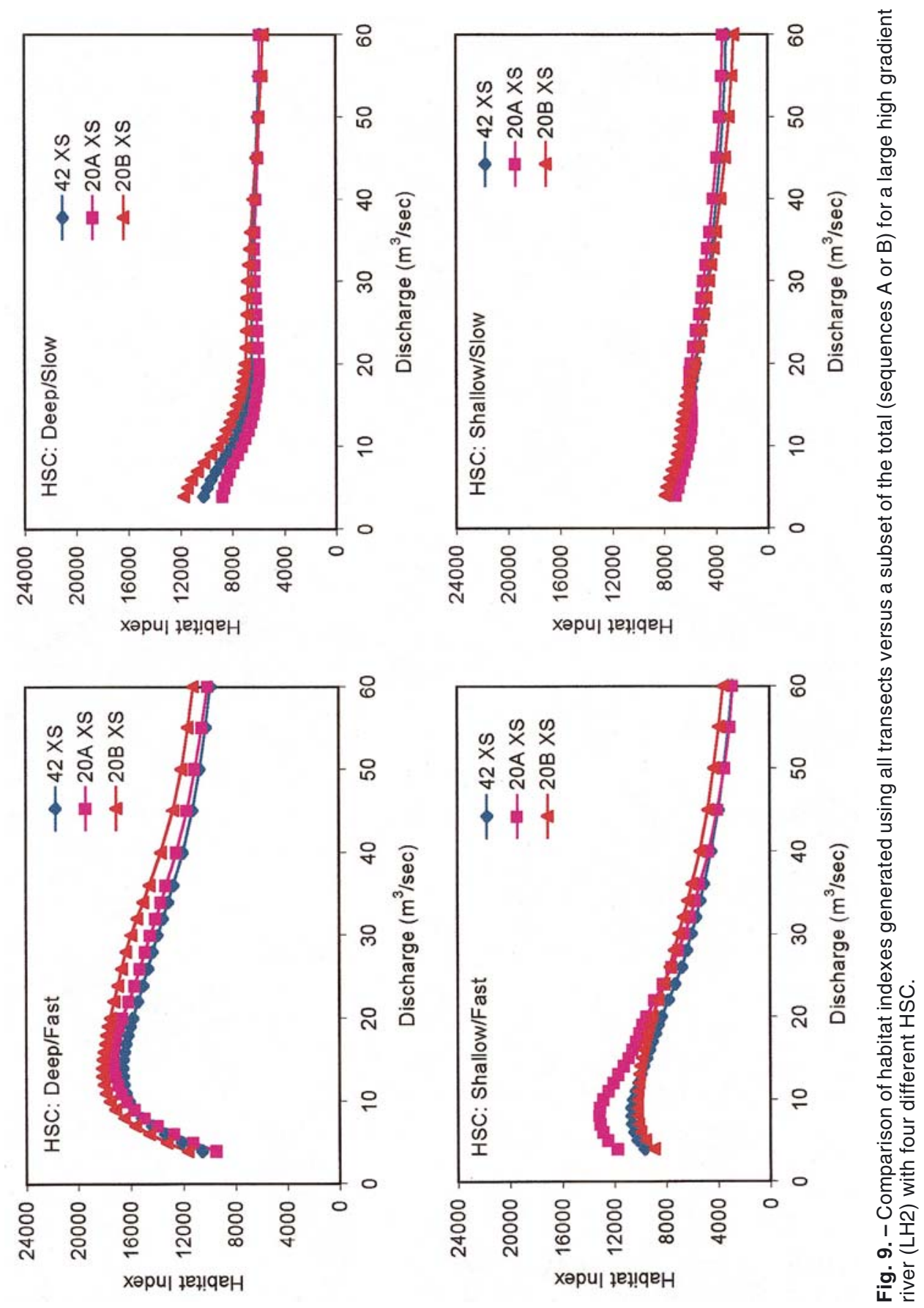

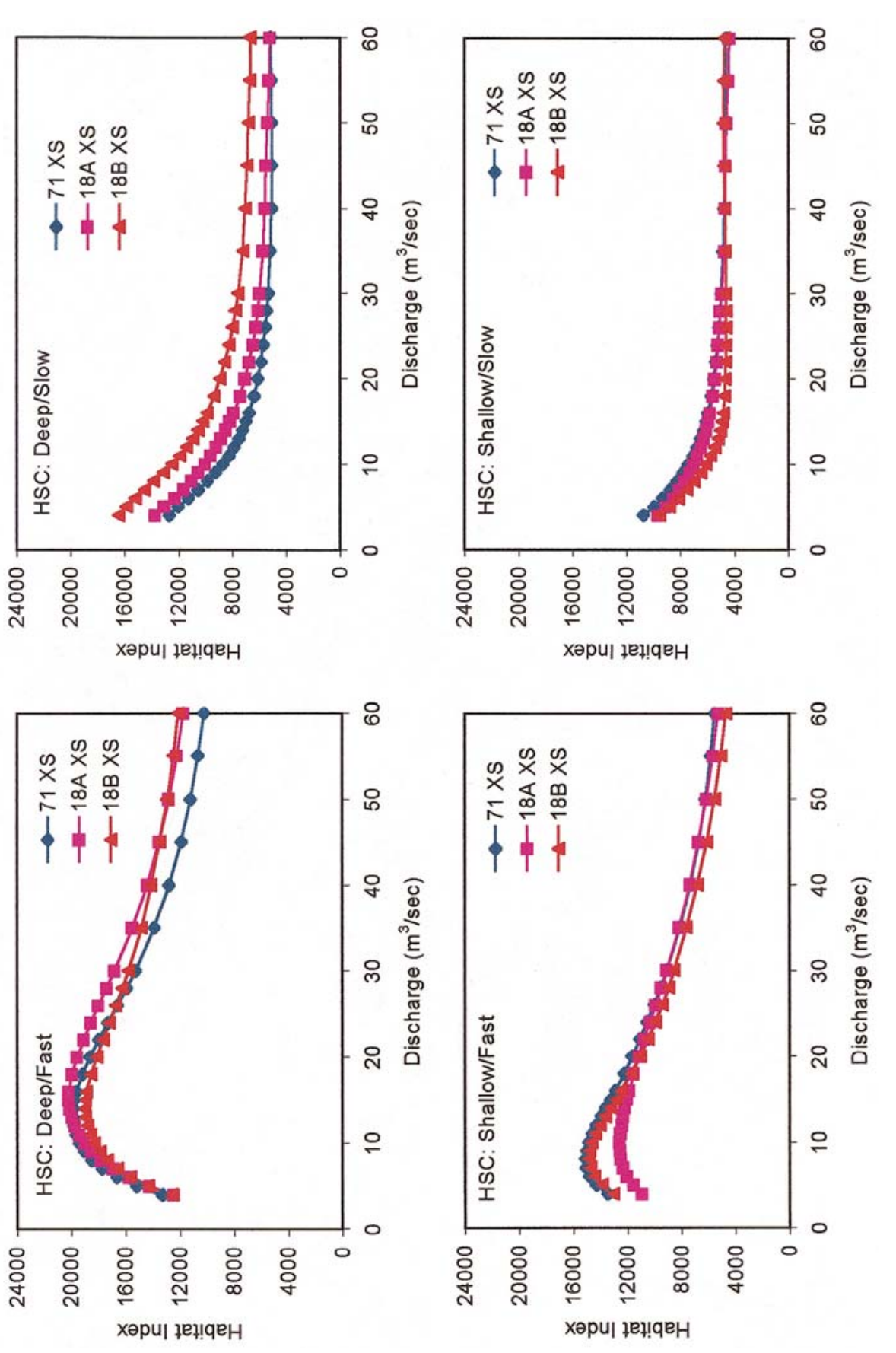

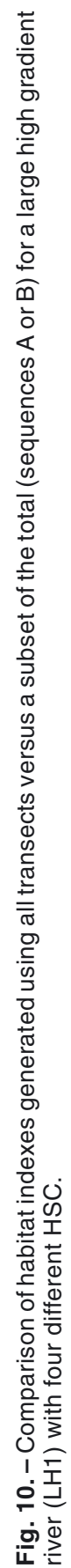



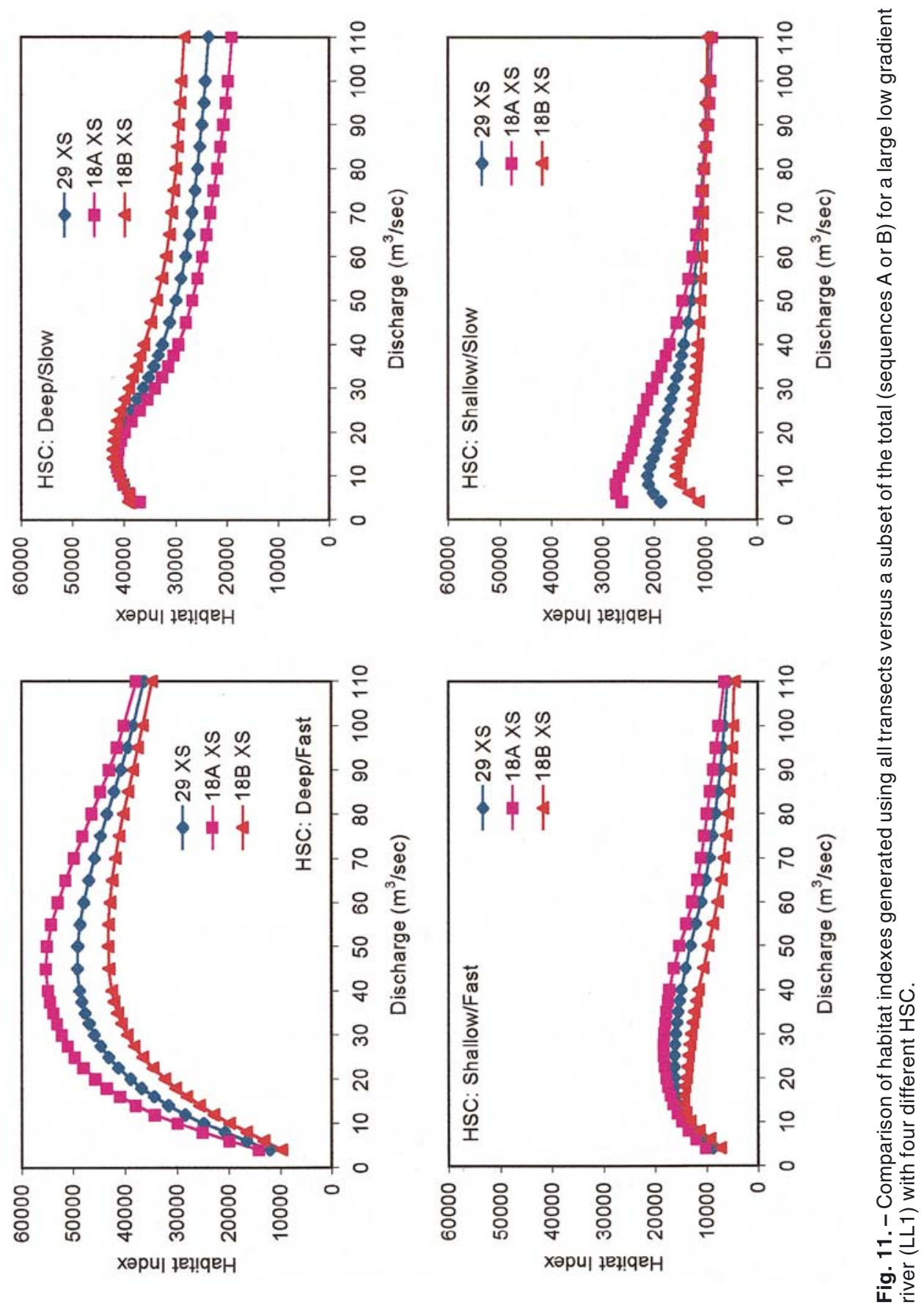

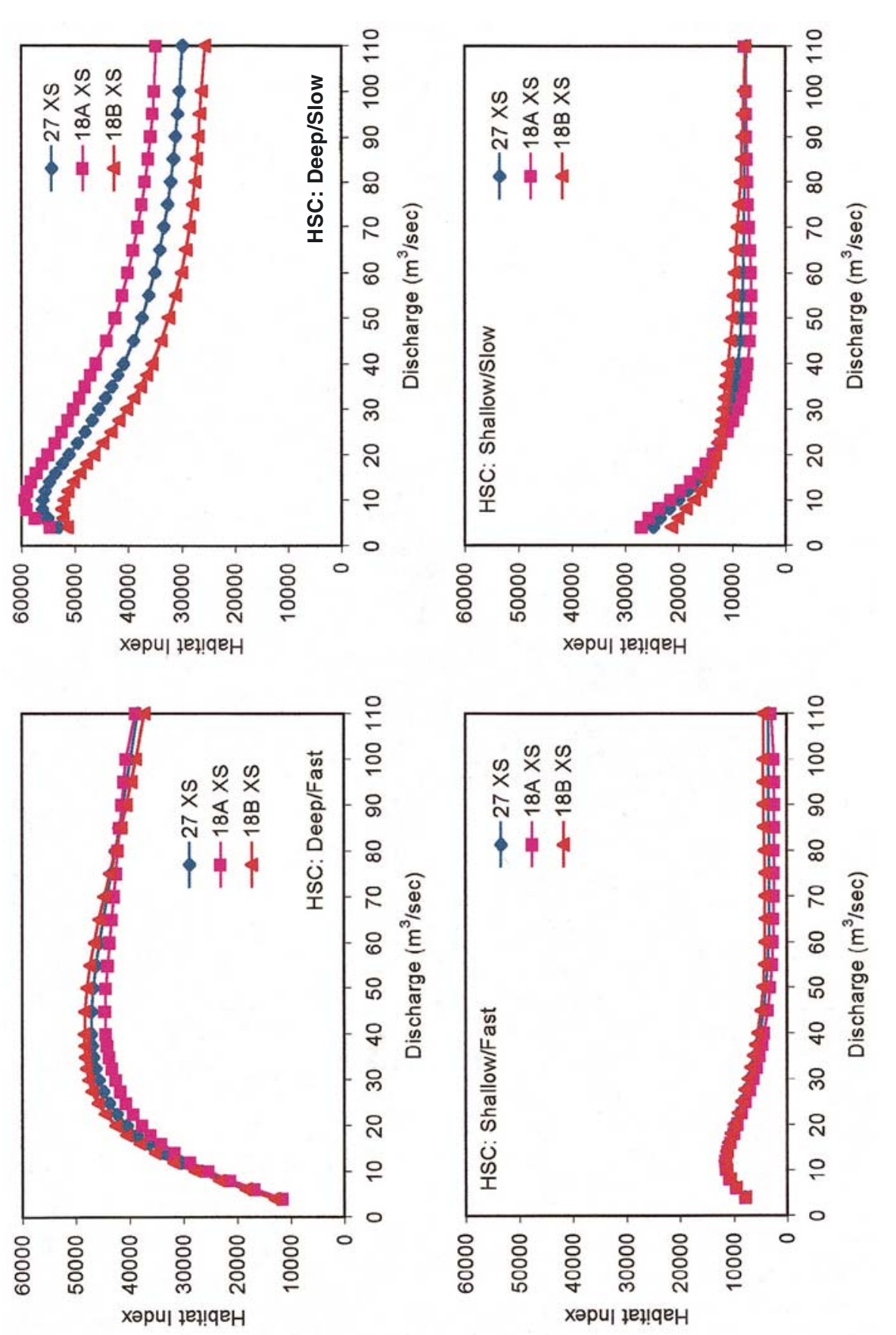

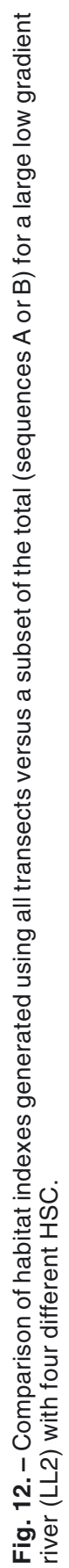



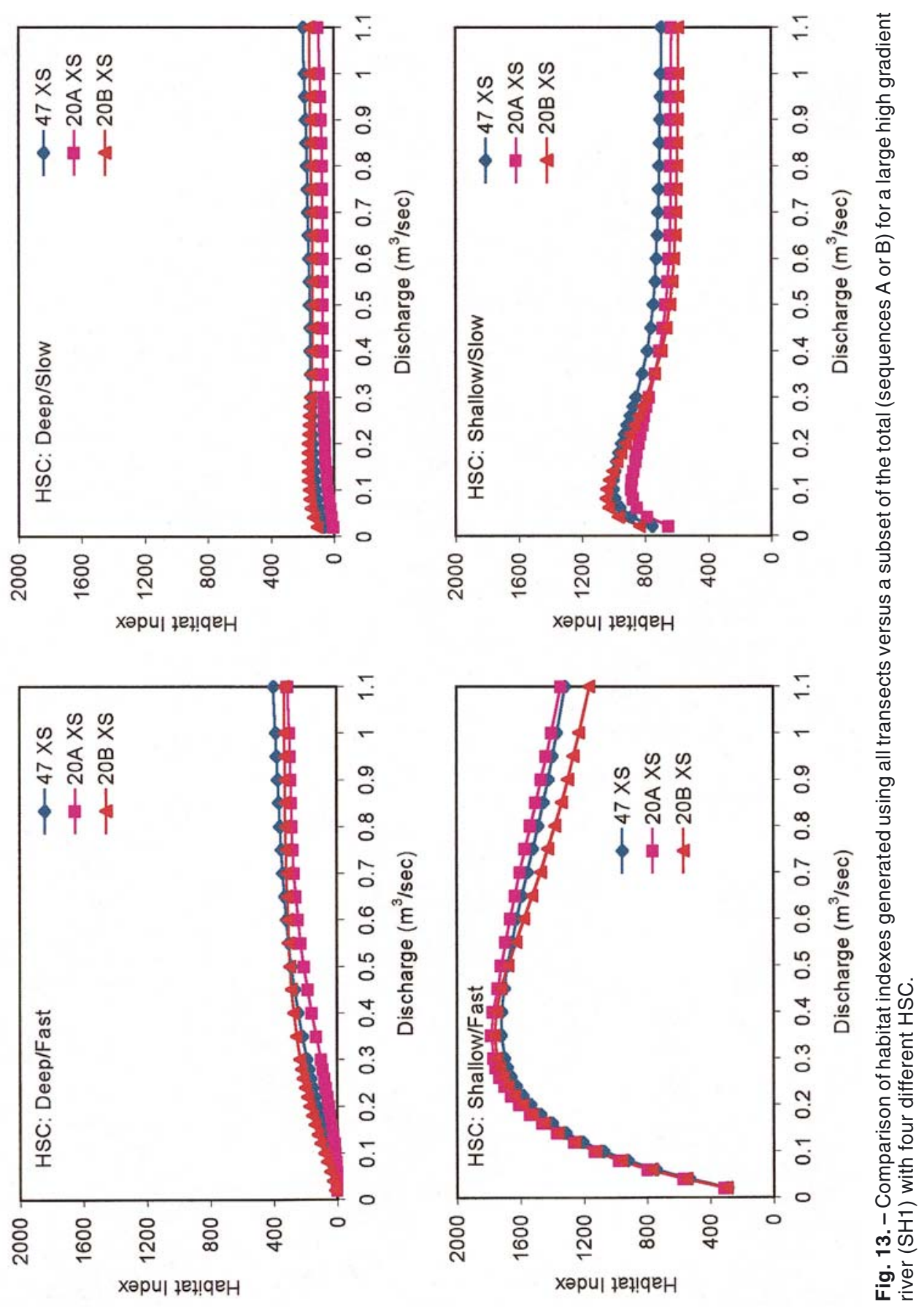

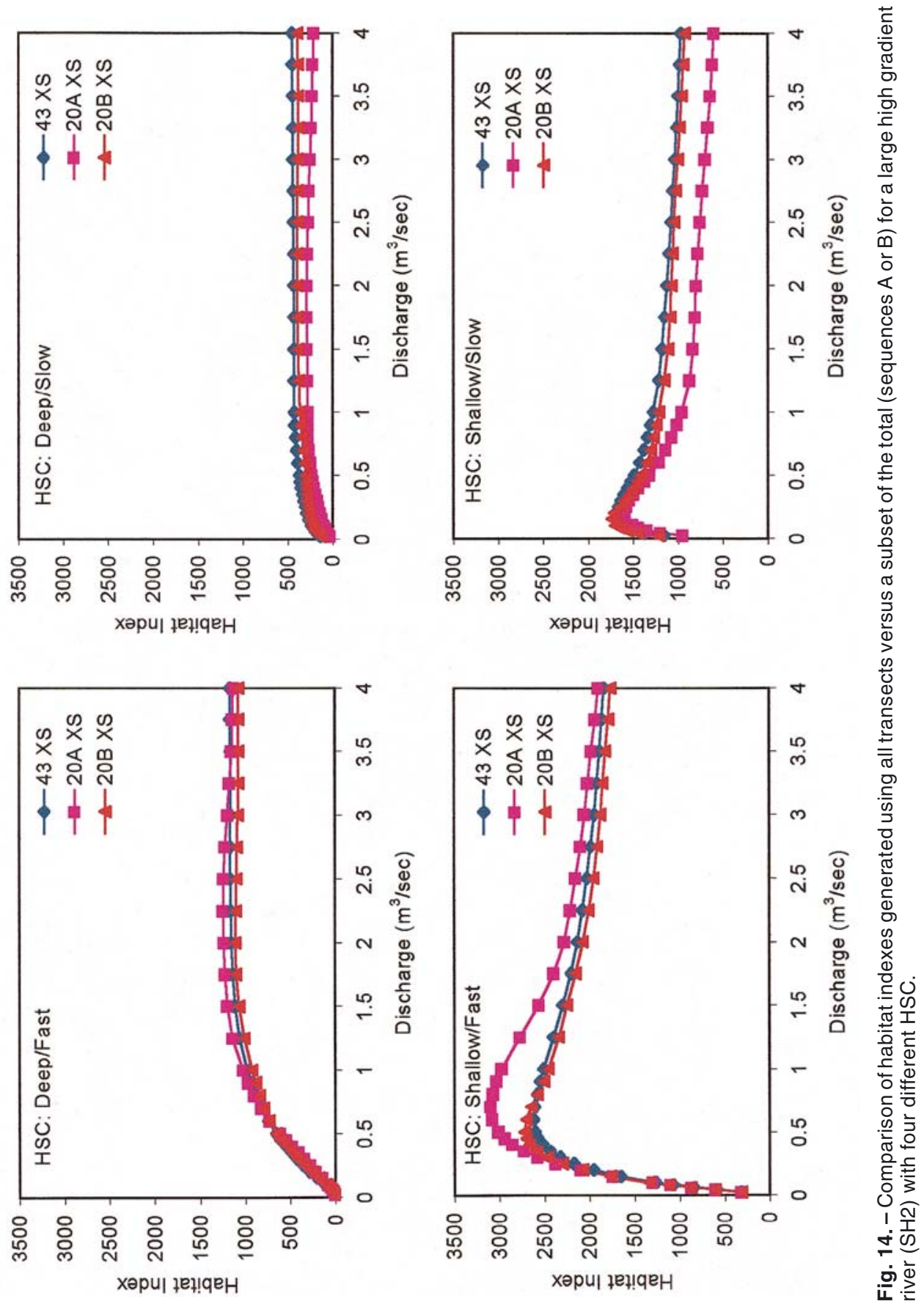


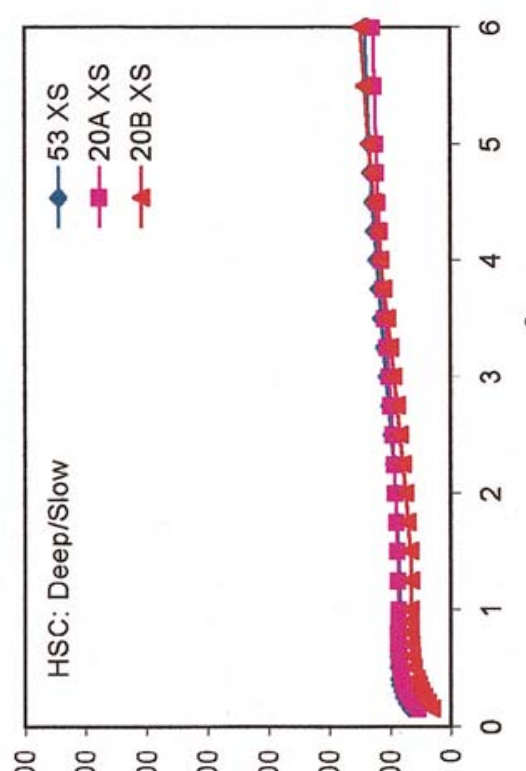

总总总

xәрuі ґең!qeH

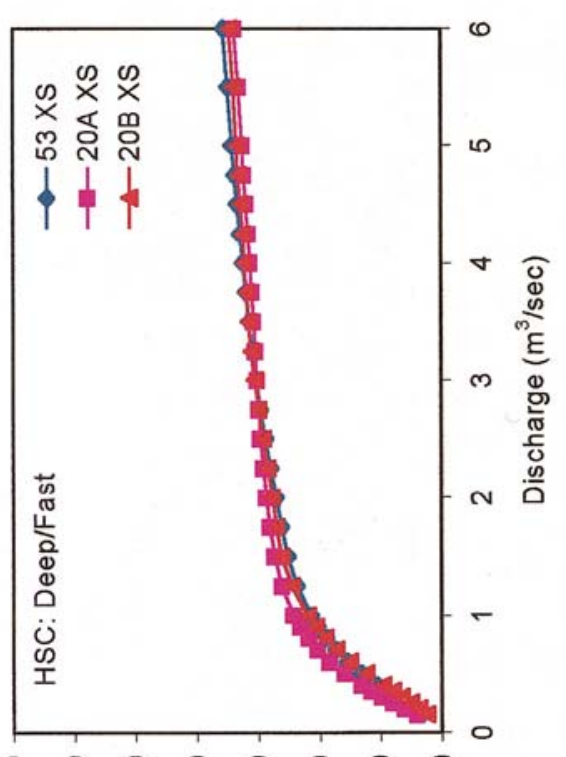

总 xәрul tel!qeH
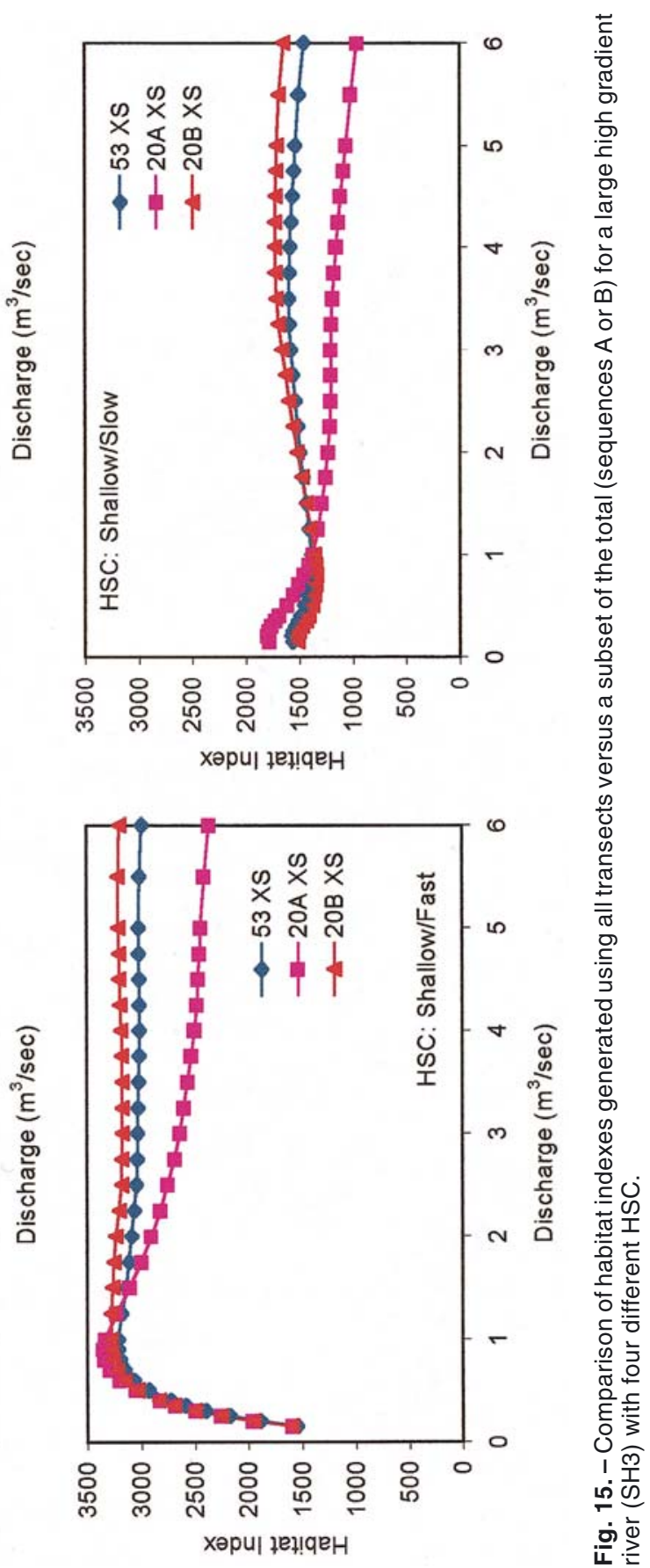

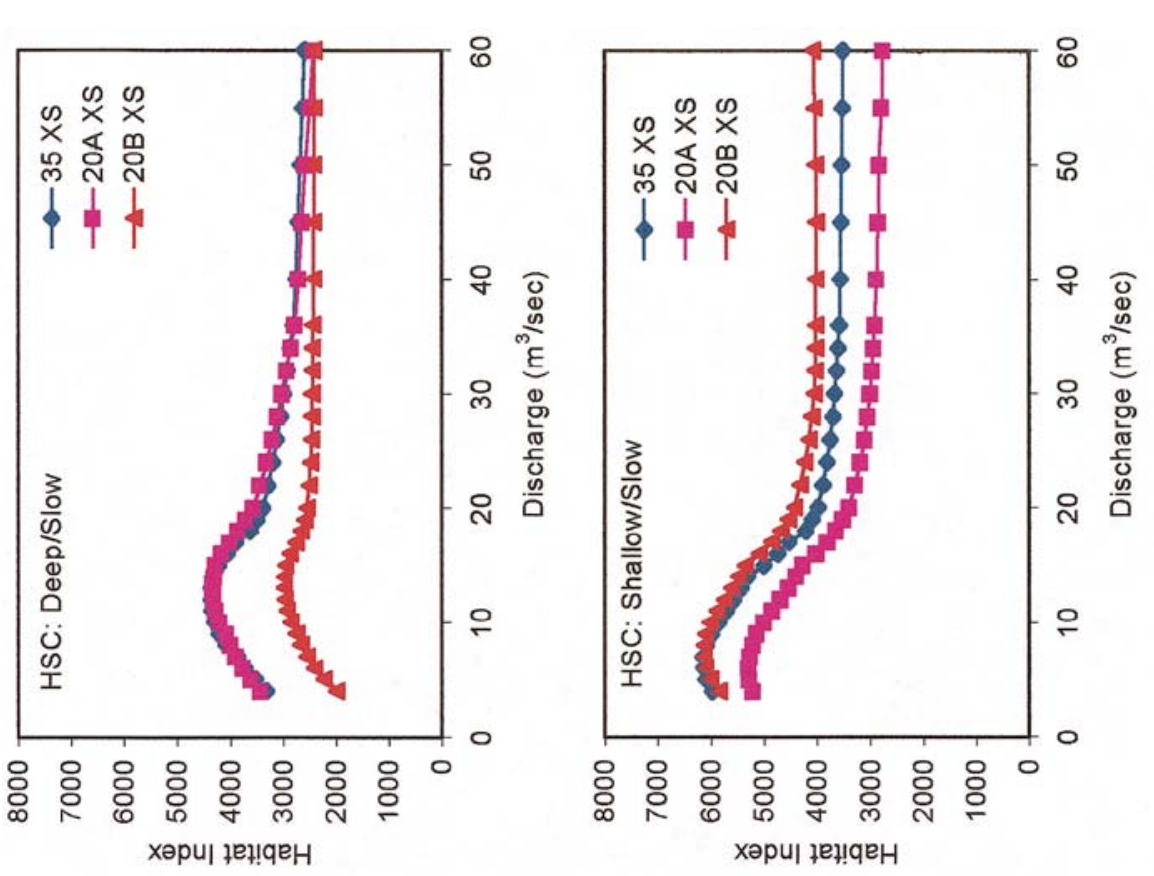

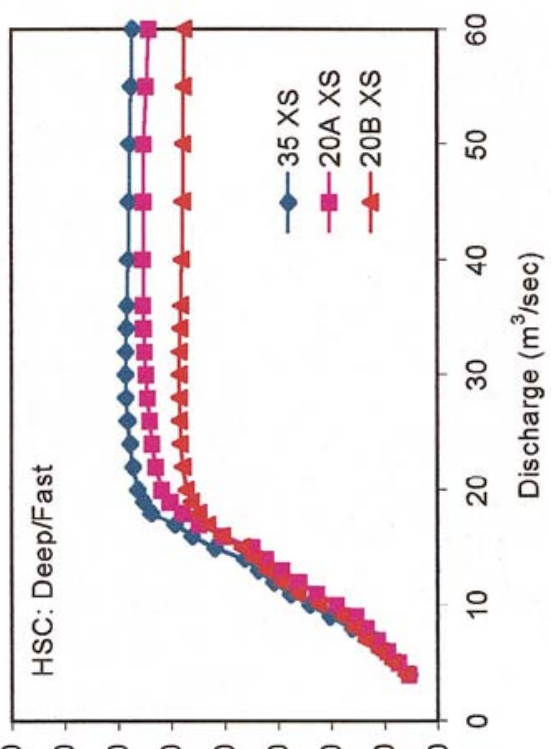

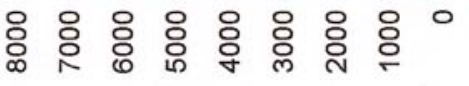
xәрuा jet!qeH

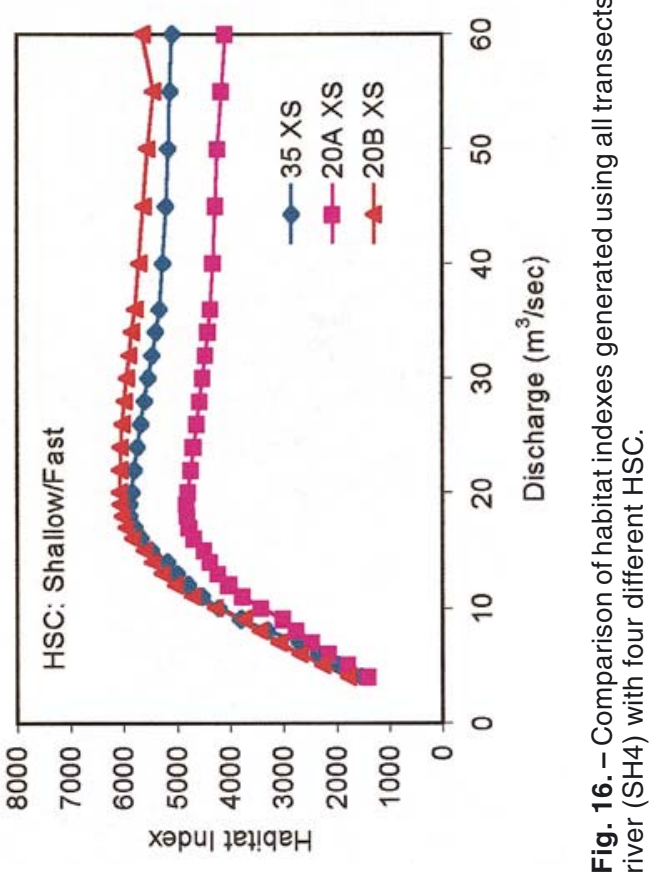


low about $10 \%$, this effect was dampened, even when more-extreme outliers were included. Third, results for all four generic HSC showed similar patterns for all eight example rivers. The similarity was evident despite the fact that some of the HSC could be considered less applicable to some of the example rivers (e.g. deep/fast criteria, or large, strong fish, in small high gradient streams), and generated low-magnitude indices due to overall lack of suitable conditions.

It could be argued that the habitat index results produced by the two subsample sets of 18-20 transects remain slightly different from each other and from the total sample, either in amplitude or the flow where the functions peak. However, the significance of these differences depends on the intended purpose and use of the instream flow study. When used as designed by the creators of the IFIM, (incorporation of the habitat index into a hydrologic time series for the analysis of alternatives), there is little functional consequence of the differences and 18-20 transects are sufficient. If the study is conducted or interpreted for rule making or standard setting purposes using either peak of the curve or percentage of the peak methods, then there could be a consequence of the differences and more transects are likely to be necessary. As Milhous (1990) noted, "In the final analysis, data collected for an instream flow study is of value only if the data influences the decision being made."
The following general guidelines for transect number and placement are offered:

- The total number of transects should be proportional to the complexity of the habitat hydraulics: 6 10 for simple reaches and 18-20 for diverse reaches

- The number of transects needed to generate a robust index applies to instream flow decision-making river segments, not individual sampling sites or reaches

- Transects should be placed in proportion to the abundance by length of the habitat type strata used, with no individual transect given a weight of more than $5-10 \%$, to minimize the influence of outliers

- Appropriate habitat type stratification and proper transect weighting by habitat type are important features of an adequate PHABSIM study

- Habitat indices should always be plotted for individual transects and reviewed for the presence of outliers and the reasons for each evaluated and understood

- Unless this type of review is conducted, unstable composite habitat index results can be created and flawed instream flow decisions can be made.

\section{REFERENCES}

Bourgeois, G., D. Caissie, and N. El-Jabi. 1996. Sensitivity analysis of PHABSIM in a small Atlantic salmon stream. Pages B381-B394 in Leclerc, M., H. Ca- 
pro, S. Valentin, A. Boudreault, and Y. Cote (eds.). Proceedings of the Second International Symposium on Habitat Hydraulics, Quebec.

Bovee, K.D. 1997. Data collection procedures for the Physical Habitat Simulation System. U.S. Geological Survey, Biological Resources Division, Ft. Collins, CO. $141 \mathrm{pp}$.

Bovee, K.D., and R.T. Milhous. 1978. Hydraulic simulation in instream flow studies: theory and techniques. Instream Flow Information Paper 5. United States Fish and Wildlife Service FWS/ OBS-78/33. 129pp.

Bovee, K.D., B.L. Lamb, J.M. Bartholow, C.B. Stalnaker, J. Taylor, and J. Henriksen. 1998. Stream habitat analysis using the Instream Flow Incremental Methodology. U.S.Geological Survey, Biological Resources Division Information and Technology Report USGS/ BRD-1998-0004. viii + 131 pp.

Leopold, L.B., M.G. Wolman, and J.P. Miller. 1964. Fluvial Process in Geomorphology. W.H. Freeman and Co., San Francisco, CA. 522pp.

Milhous, R. T. 1990. User's Guide to the Physical Habitat Simulation System Version II. Instream Flow Information Paper No. 32. U.S. Fish and Wildlife Service Biological Report. 380 p.
Morhardt, J.E., D.F. Hanson, and P.J. Coulston. 1983. Instream flow: improved accuracy through habitat mapping. In Waterpower '83: International Conference on Hydropower (Vol III, pp. 1294-1304). September 1983, Knoxville, Tennessee.

Morhardt, J.E. 1986. Instream flow methodologies. Research Project 2194-2, Completion report, Electric Power Research Institute, Palo Alto, California by EA Engineering, Science, and Technology, Inc., Lafayette, California, September 1986. 306pp + apps.

Simonson, T.D., J. Lyons, and P.D. Kanehl. 1994. Quantifying fish habitat in streams: transect spacing, sample size, and a proposed framework. North American Journal of Fisheries Management, 14: 607-615.

Stalnaker, C.B., B.L. Lamb, J. Henriksen, K. Bovee, and J. Bartholow. 1995. The Instream Flow Incremental Methodology, a primer for IFIM. National Biological Service, U.S. Department of the Interior. Biological Report 29, March 1995. 45pp.

Williams, J.G. 1996. Lost in space: minimum confidence intervals for idealized PHABSIM studies. Transactions of the American Fisheries Society 125: 458465. 
